\title{
Overwintering Physiology and Cold Tolerance of the Sunn Pest, Eurygaster integriceps, an Emphasis on the Role of Cryoprotectants
}

\author{
Hamzeh Hasanvand, Hamzeh Izadi* and Mozhgan Mohammadzadeh \\ Department of Plant Protection, Faculty of Agriculture, Vali-e-Asr University of Rafsanjan, Rafsanjan, Iran
}

As a serious pest of wheat, the Sunn pest, Eurygaster integriceps Puton (Hem.: Scutelleridae), is prevalent in Iran. This pest belongs to univoltine species and tends to estivate and overwinter in high altitudes of nearby mountains as diapausing adults. The economic importance of the crop was attacked by this pest, i.e., wheat led the authors to study the physiological adaptations of these diapausing adults, that is, changes in the supercooling point (SCP), in the accumulation of cryoprotectants, and in the activities of the related enzymes in relation to diapause development. The mean SCP of the

OPEN ACCESS

Edited by:

Bin Tang,

Hangzhou Normal University, China

Reviewed by:

Wen Liu,

Huazhong Agricultural University,

China

Mohammad Mehrabadi,

Tarbiat Modares University, Iran

Shaohui Wu,

University of Georgia, United States

*Correspondence: Hamzeh Izadi izadi@vru.ac.ir

Specialty section: This article was submitted to

Invertebrate Physiology,

a section of the journa

Frontiers in Physiology

Received: 13 December 2019 Accepted: 20 March 2020

Published: 30 April 2020

Citation:

Hasanvand $\mathrm{H}$, Izadi $\mathrm{H}$ and Mohammadzadeh M (2020)

Overwintering Physiology and Cold

Tolerance of the Sunn Pest,

Eurygaster integriceps, an Emphasis on the Role of Cryoprotectants.

Front. Physiol. 11:321. doi: 10.3389/fphys.2020.00321 diapausing adults was found to be $-8^{\circ} \mathrm{C}$. The lowest SCP, i.e., approximately $-11^{\circ} \mathrm{C}$, was observed in the middle of diapause, October, when the highest cold hardiness was also interestingly recorded. This finding proposed that SCP depression could be a feasible cold-tolerance strategy for diapausing adults. The sugar content was high in the initiation and at the termination of diapause and was low during diapause maintenance. These sugar reserves were most likely utilized to be converted to glycogen and lipid during diapause maintenance as a survival strategy. The changes in the glycogen and lipid contents were inversely proportional to the changes in the total sugar content. The authors also found that the changes in the glycogen content were directly proportional to those in the low-molecular-weight carbohydrates (e.g., glycerol and trehalose) and in the diapause development. This finding underlined the role of the low-molecularweight carbohydrates, such as the cryoprotectants, in enhancing the cold tolerance of the given insect. In this study, the diapause-associated changes in the activities of $\alpha$-amylases and proteases were also investigated. The results showed that the enzyme activities were related to diapause development and cold-tolerance enhancement. The highest enzyme activity was observed in September. Since the overwintering adults of the Sunn pest could not tolerate temperatures below their SCPs, they were grouped in the freeze-intolerant species.

Keywords: Sunn pest, supercooling point, cold tolerance, polyols, diapause

\section{INTRODUCTION}

The ambient temperature can directly affect different stages of the life cycle of insects, as an ectothermic group of animals, including growth, development, reproduction, survival, and distribution (Régničre et al., 2012; Jaworski and Hilszczański, 2014). A large number of insects living in the places where the environment faces seasonal variations tend to enter diapause to 
circumvent adversities in the environment. The mechanism adopted by the insects to avoid adversities in the environment is known as diapause (specified arrest of development), during which temperature, photoperiod, and/or food quality encourage some pre-programmed physiological changes, thus leading to the suppression of metabolism, the enhancement of resistance to cellular stress, and the onset of dormancy in advance of unfavorable environmental conditions (Poelchau et al., 2013; Roncalli et al., 2018). The suppression of insect metabolism and the cessation of direct development lead to the regulation of the timing of growth, maturation, and reproduction. Finally, the optimum conditions in the environment can eventually harmonize the development of insects (Roncalli et al., 2018).

The Sunn pest, Eurygaster integriceps Puton (Hem.: Scutelleridae), is a key pest of wheat in the west and central Asia and remains a serious pest in wheat-producing areas of Iran. E. integriceps is a univoltine pest overwintering as a diapausing adult. The diapausing adults migrate to mountains during June-July and following wheat harvest and overwinter beneath litter layers under shrubs and trees. Moreover, in this species, diapause is induced in advance of the advent of harsh environmental conditions. The overwintering adult migrates back to the cereal fields in the following spring (March-April) (Iranipour et al., 2010; Parker et al., 2011; Davari and Parker, 2018) (Figure 1).

One of the cryptobiotic states observed during the ontogenesis of insects is diapause, in which the metabolic processes markedly reduce. Within this period, the species undergo diapause as a cryptobiotic (deep metabolism suppression) phase of the insect's ontogenesis, during which direct development is arrested, and the species shows no visible signs of life (Koštál, 2006; Hand et al., 2016; Diniz et al., 2017). The diapause periods in insects can be categorized as pre-diapause, diapause, and post-diapause, each of which has several subcategories (Koštál, 2006). The first period, namely, pre-diapause (e.g., May-June), includes two sub-phases, i.e., induction and preparation, during which the species prepares itself for the suspended development or the diapause. This period is followed by the diapause, which itself includes three sub-phases, i.e., initiation (July-September in our research), maintenance (October-November in our research), and termination (December-March in our research). Initiation is mainly characterized by the arrest of development and strong suppression of metabolism period. The morphogenetic, metabolic, and reproductive traits of the insects then halt in the next subcategory, i.e., maintenance, lasting for a couple of weeks or months. Termination, eventually, is marked by the renewal of the signs of life in the species, resulting from photoperiod, several endogenous processes, and temperature changes in the environment. Here, metabolism quickly normalizes (Koštál, 2006; Hand et al., 2016; Diniz et al., 2017).

Cold hardiness or cold tolerance is the ability of an insect to resist long- or short-term exposure to low temperatures (Lee et al., 1991; Sinclair et al., 2015). The extent to which ambient temperature affects the survival and reproduction of insects is determined by the development of cold hardiness in insects (Feng et al., 2018). Diapause and cold hardiness are both adaptation strategies exploited by most insects to survive from sub-zero temperatures in temperate zones (Denlinger, 1991; Storey and Storey, 2004). However, the relationship between these two strategies is not clear. In some insects, these two are independent phenomena (Goto et al., 2001; Khanmohamadi et al., 2016; Mollaei et al., 2016; Mohammadzadeh et al., 2017), while in some other insects, cold hardiness is a component of the diapause syndrome (Milonas, 1999; Bemani et al., 2012; Heydari and Izadi, 2014; Cira et al., 2018). In most insects, development of cold hardiness is highly associated with some physiological adaptations, e.g., synthesis and accumulation of low-molecularweight carbohydrates and polyols (cryoprotection) (Behroozi et al., 2012; Vrba et al., 2017; Mohammadzadeh and Izadi, 2018a,b; Izadi et al., 2019), synthesis of antifreeze proteins or carbohydrates (Costanzo and Lee, 2013; Khanmohamadi et al., 2016; Mollaei et al., 2016), use of cryoprotective dehydration (Elnitsky et al., 2008; Clark et al., 2009; Worland et al., 2010), and regulation of ice nucleation (Costanzo and Lee, 2013).

The temperature at which fluids in the body of insects start freezing is defined as the supercooling point (SCP). The SCP is experimentally determined by the measurement of the exotherm released by the latent heat of water fusion during cooling exposure. Investigations on the strategies adopted by insects to develop cold tolerance usually begin with the preliminary measurement of SCP (Sinclair et al., 2015; Ditrich, 2018). These strategies can be categorized into three groups: chill-susceptible strategy (in which insects die even after a brief exposure to sub-zero temperatures), freeze-avoidance strategy (in which insects can tolerate moderate to high sub-zero temperatures but without internal ice formation, i.e., supercooled state), and freeze-tolerance strategy (in which insects can tolerate internal ice formation) (Sinclair, 1999; Sinclair et al., 2015).

Three main digestive enzymes, including proteases, amylases, and lipases, facilitate the digestion of macromolecules existing in the food. Amylase, as a glycoside hydrolase enzyme, functions as a catalyzer to hydrolyze the glycosidic bonds of polysaccharides, such as starch and glycogen, thus breaking them down into mono and/or disaccharides. Depending on the type of bond they form, namely, $\alpha$ or $\beta$, this group has two major enzymes, that is, $\alpha$ amylase and $\beta$-amylase. Another hydrolase enzyme is proteases, catalyzing the hydrolysis of peptide linkages of proteins and releasing amino acids from protein. Both of the aforementioned enzymes are vital for digesting food efficiently (Nation, 2015).

Cryoprotectants can be synthesized and accumulated to increase cold hardiness of many insects, the most prevalent of which include polyhydric alcohols (e.g., glycerol), low-molecularweight carbohydrates (e.g., trehalose), and amino acids (Fuller, 2004). Amino acids can lower the non-colligative freezing points of water, thus functioning as an antifreeze compound. It may also increase the solute concentration of fluids of the body of insects, thereby acting as a cryoprotectant (Zachariassen, 1985; Li, 2012). Antifreeze (IFP) or ice-binding proteins were categorized into three major groups (Duman, 2015), that is, ice-binding proteins, which typically do their antifreeze actions by great thermal hysteresis, antifreeze proteins, which generally follow their antifreeze actions by low thermal hysteresis, and ice-nucleating proteins, which seemingly prevent intracellular ice formation via forming a template around the ice. Thus, the 


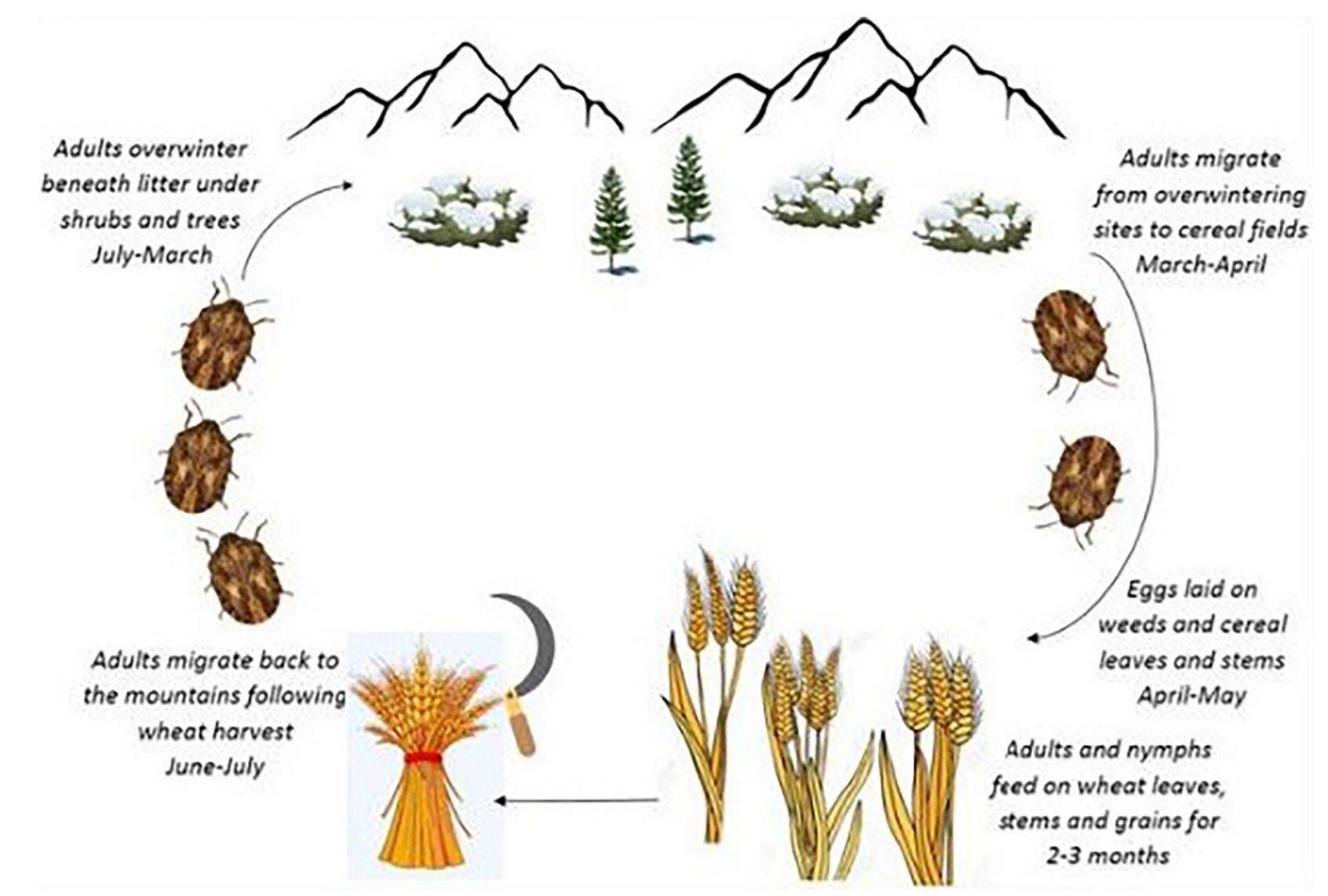

FIGURE 1 | Life cycle of Eurygaster integriceps "adapted with permission" from Davari and Parker (2018).

formation of ice securely occurs in the extracellular fluid of the body, where no fatal intracellular ice crystallizes. As the simple biomolecules, cryoprotectants, however, are generally created through the metabolic activities of a number of enzymes (Storey and Storey, 1991; Walters et al., 2009). The main classes of cryoprotectants, polyols, are usually formed in tissues of insects, when glycogen, as the substrate, is employed in various enzymatic biochemical processes (Lee, 2010). Different media, including pyruvate, oxaloacetate, $\alpha$-ketoglutarate, and 3-phosphoglycerate, can form amino acids via different enzymatic biochemical mechanisms (e.g., citric acid cycle). In this study, the authors made an effort to study the impact of two enzymes, i.e., amylase and protease, to understand how these enzyme activities might relate to cold tolerance in the overwintering adults of E. integriceps. The correlation between diapause development and cold hardiness was also examined. Additionally, the influence of some metabolites upon cold hardiness of E. integriceps was studied within the 9-month period of diapause.

\section{MATERIALS AND METHODS}

The mature pests of E. integriceps were gathered monthly (from July to March) from overwintering sites in Lorestan province $\left(48^{\circ}, 19^{\prime}, 22^{\prime \prime} \mathrm{N}, 23^{\circ}, 50^{\prime}, 11^{\prime \prime} \mathrm{E}\right.$, and altitude of $\left.1,943 \mathrm{~m}\right)$, Iran. The conditions under which the pests were preserved prior to sampling were constant. Data as to temperature changes (Figure 2) in the environment were provided by the Data Processing Center of Iran Meteorological Organization (IMO), situated close to the sampling site.

\section{Determination of SCP}

The SCPs of adults ( $n=6-10$ individuals per month) were determined using a thermocouple ( $\mathrm{NiCrNi}$ probe) connected to an automatic temperature recorder, Testo 177-T4 (Testo, Germany). The temperature was recorded every $30 \mathrm{~s}$, and the data were then read using Comsoft 3 Software. Each specimen was attached to the thermocouple by means of an adhesive tape and was placed inside a programmable refrigerated chamber (Gotech; GT-7005-A; Taiwan), whose temperature was lowered at a rate of $0.5^{\circ} \mathrm{C}$ per minute. The SCP was taken as an abrupt temperature increase occurring with the release of the latent heat of crystallization (Mohammadzadeh and Izadi, 2016).

\section{Cold Tolerance Assay}

Cold tolerance of the adults was assayed by cooling individual adults $(n=17-58)$ to $5,0,-5$, or $-10^{\circ} \mathrm{C}$ in Petri dishes. The Petri dishes were placed in a programmable refrigerated test 


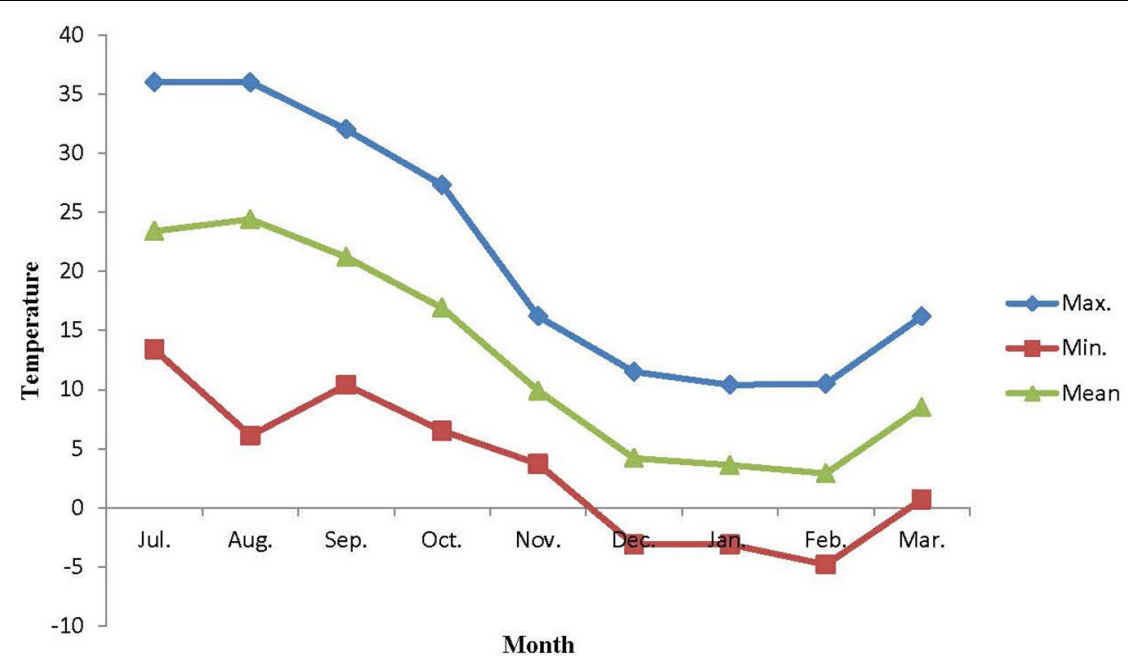

FIGURE 2 | Ambient temperature of overwintering habitats of Eurygaster integriceps during different overwintering months of 2015-2016.

chamber (Gotech; GT-7005-A; Taiwan). The temperature was lowered from $25^{\circ} \mathrm{C}$ to the desired treatment temperature at a rate of $0.5^{\circ} \mathrm{C}$ per minute. At each set temperature, the adults were removed after $24 \mathrm{~h}$ and returned to an optimal temperature $\left(25 \pm 1^{\circ} \mathrm{C}\right)$. The live and dead adults were counted after $24 \mathrm{~h}$ (Mohammadzadeh and Izadi, 2016).

\section{Weight and Water Quantification}

The adults ( $n=6$ per month) were separately weighed and dried in an oven at $65^{\circ} \mathrm{C}$ for $72 \mathrm{~h}$. The water content $(\mathrm{w} / \mathrm{w})$ was obtained from subtracting dry weight from fresh weight and then dividing the result by fresh weight (Lehmann et al., 2012; Heydari and Izadi, 2014).

\section{Total Body Sugars Quantification}

The total simple sugars (monosaccharides and disaccharides) were determined using the anthrone reagent method proposed by Warburg and Yuval (1997). Briefly, individual adults were weighed and homogenized with a homogenizer (Teflon pestle; $0.1 \mathrm{~mm}$ clearance) in $200 \mu \mathrm{l}$ of $2 \% \mathrm{Na}_{2} \mathrm{SO}_{4}$. In order to extract the simple sugars, $1,300 \mu \mathrm{l}$ of a chloroform-methanol mixture (1:2) was initially added to the homogenate and centrifuged at $7,150 \times g$ for $10 \mathrm{~min}$. Next, $300 \mu \mathrm{l}$ of the supernatant was mixed with $200 \mu \mathrm{l}$ of distilled water and reacted with $1 \mathrm{ml}$ of the anthrone reagent $(500 \mathrm{mg}$ of anthrone dissolved in $500 \mathrm{ml}$ of concentrated $\mathrm{H}_{2} \mathrm{SO}_{4}$ ) for $10 \mathrm{~min}$ at $90^{\circ} \mathrm{C}$. The amount of total simple sugars was determined at $630 \mathrm{~nm}$ using a spectrophotometer (T60U; Harlow Scientific, United States). Glucose (Sigma) was used as a standard. This experiment was carried out per month using six adults, each as a replicate (Heydari and Izadi, 2014; Mohammadzadeh and Izadi, 2016).

\section{Glycogen Determination}

The pellet obtained from the analysis of total body sugars was used for the determination of glycogen content. To remove the possible remnants of sugar, the pellet was washed with $400 \mu \mathrm{l}$ of $80 \%$ methanol and mixed with $250 \mu \mathrm{l}$ of distilled water. This mixture was heated at $70^{\circ} \mathrm{C}$ for $5 \mathrm{~min}$. Next, $200 \mu \mathrm{l}$ of the solution was removed and reacted with $1 \mathrm{ml}$ of the anthrone reagent $(600 \mathrm{mg}$ of anthrone dissolved in $300 \mathrm{ml}$ of the concentrated $\mathrm{H}_{2} \mathrm{SO}_{4}$ ) for $10 \mathrm{~min}$ at $90^{\circ} \mathrm{C}$. The optical density was read at $630 \mathrm{~nm}$ on a spectrophotometer (T60U; Harlow Scientific, United States). Glycogen (Sigma) was used as a standard. This experiment was carried out per month using six individuals, each as a replicate (Heydari and Izadi, 2014; Mohammadzadeh and Izadi, 2016).

\section{Low-Molecular-Weight Carbohydrates and Polyol Assay}

To determine low-molecular-weight carbohydrates and polyols (trehalose, glucose, glycerol, and myo-inositol), the adult bugs were weighed, homogenized in $1.5-2 \mathrm{ml}$ of $80 \%$ ethanol with the pre-cooled homogenizer (Teflon pestle), having a clearance of $0.1 \mathrm{~mm}$, and centrifuged at $12,000 \times g$ for $15 \mathrm{~min}$. The supernatant was evaporated in a vacuum drying oven at $40^{\circ} \mathrm{C}$ and then resuspended in $1 \mathrm{ml}$ of HPLC-grade water. The samples were passed through a $20-\mu \mathrm{m}$ syringe filter and analyzed by high-performance liquid chromatography (Knauer, Berlin, Germany) equipped with a carbohydrate column having $4-\mu \mathrm{m}$ particle size $(250 \mathrm{~mm} \times 4.6 \mathrm{~mm}$, I.D.; Waters, Ireland). Acetonitrile-water (70:30) was used as eluent. The elution speed was $1 \mathrm{ml} / \mathrm{min}^{-1}$, and the separation was achieved at $40 \pm 1^{\circ} \mathrm{C}$. Twenty microliters of the whole-body extracts along with the standard of each carbohydrate from 1,500 to 5,500 ppm were run. This experiment was carried out per month using six individuals, each as a replicate (Heydari and Izadi, 2014; Mohammadzadeh and Izadi, 2016).

\section{Enzymes Assay \\ Preparation of the Samples}

The adult bugs were anesthetized on ice slurry and decapitated. The midgut was gently removed with the aid 
of a stereomicroscope (Stemi SV6 ZEISS; Germany) and placed in $1.5-\mathrm{ml} \mathrm{microtubes}$ containing $1.0 \mathrm{ml}$ of cooled distilled water. Out of each sample, 10 midguts underwent the mentioned process. The samples were homogenized and centrifuged at $15,000 \times g$ for $15 \mathrm{~min}$ at $4^{\circ} \mathrm{C}$. The supernatant was used for the enzymatic assays (Borzoui et al., 2015; Mohammadzadeh and Izadi, 2016).

\section{Amylase Activity Assay}

Amylolytic activity of $\alpha$-amylase was determined based on the procedure proposed by Bernfeld (1955). A mixture of $40 \mu \mathrm{l}$ of $1 \%$ freshly prepared starch solution, $500 \mu \mathrm{l}$ of $20 \mathrm{mM}$ phosphate buffer ( $\mathrm{pH} \mathrm{7)}$, and $20 \mu \mathrm{l}$ of enzyme extracts was prepared and incubated for $30 \mathrm{~min}$ at $37^{\circ} \mathrm{C}$. Then, $100 \mu \mathrm{l}$ of the 3,5-dinitrosalicylic acid (DNS) reagent was added to the mixture and heated in boiling water for $10 \mathrm{~min}$ to stop the reaction. The optical density (OD) was measured at $540 \mathrm{~nm}$ using a spectrophotometer (T60U; Harlow Scientific, United States). Maltose (Sigma) was used as a standard, and the amylolytic activity was determined from a standard curve. The experiments were run in five replicates with blanks containing no enzyme extracts.

\section{Protease Activity Assay}

The azocasein method was used to assay the digestive proteolytic activity of E. integriceps adults collected during a period of several months (Gatehouse et al., 1999; Elpidina et al., 2001), albeit a number of modifications were made based on Mohammadzadeh and Izadi (2018b). A mixture of $10 \mu \mathrm{l}$ of midgut homogenate, $40 \mu \mathrm{l}$ of glycine- $\mathrm{NaOH}$ buffer ( $\mathrm{pH} 10)$, and $50 \mu \mathrm{l}$ of $2 \%$ azocasein substrate was incubated for $60 \mathrm{~min}$ at $37^{\circ} \mathrm{C}$. By adding $100 \mu \mathrm{l}$ of $30 \%$ trichloroacetic acid, the reaction halted. The mixture was held for $30 \mathrm{~min}$ at $4^{\circ} \mathrm{C}$ and then centrifuged at 10,000 $\times g$ for $15 \mathrm{~min}$. The supernatant was dissolved in an equal volume of $1.0 \mathrm{M} \mathrm{NaOH}$. The absorbance was recorded at $405 \mathrm{~nm}$. All assays were run in five replicates with blanks containing trichloroacetic acid (TCA).

\section{Statistical Analysis}

The Kolmogorov-Smirnov test was initially performed to examine the normality of the studied data. The Levene's test was then used to indicate homoscedasticity. The one-way analysis of variance (ANOVA) and the post hoc Tukey's test $(\mathrm{P}=0.05)$ were subsequently run to compare multiple treatments. For non-normally distributed SCP data, the Mann-Whitney U and Kruskal-Wallis tests were additionally administered to trace differences observed in data.

\section{RESULTS AND DISCUSSION}

\section{The SCP Changes During Diapause}

The SCP of the overwintering adults were measured monthly from July 2015 to March 2016. The changes in SCP are presented in Figure 3. The SCPs of the diapausing adults of E. integriceps ranged from $-7.3^{\circ} \mathrm{C}$ (traced in July) to $-6.2^{\circ} \mathrm{C}$ (detected in March), exhibiting a U-shaped curve. The SCP decreased from approximately $-7^{\circ} \mathrm{C}$ (in July and August) to about $-8^{\circ} \mathrm{C}$ (in September) and finally reached the lowest level in the diapause maintenance, i.e., in October and November $\left(-1.9^{\circ} \mathrm{C}\right.$ and $-10.2^{\circ} \mathrm{C}$, respectively). From December onward, SCP increased and reached the highest level (about $-6^{\circ} \mathrm{C}$ ) at the approach of spring. The cold hardiness of E. integriceps was also investigated in the altitude of Ateshgah Karaj-Iran (see Baghdadi et al., 2001), the results of which demonstrated that SCPs varied from $-12.9^{\circ} \mathrm{C}$ (in early winter of $1998-1999$ ) to $-6.7^{\circ} \mathrm{C}$ (in 1999-2000). Similarly, the cold-tolerance strategies of the aforementioned pest were studied in altitude of Ghara-aghaj Varamin-Iran (Baghdadi, 2007), and SCPs of the overwintering species under investigation were measured. In this research, SCP reported for the coldest month of the year was $-5^{\circ} \mathrm{C}$. On the other hand, Cira et al. (2018) studied changes in SCPs of the diapausing adults of $H$. halys and concluded that SCP in October was significantly higher than that in other months of the diapause. Košál and Šimek (2000) investigated the overwintering strategy of Pyrrhocoris apterus (Heteroptera: Pyrrhocoridae) and reported the highest level of SCP at the termination of the diapause of the adult bugs. Overall, the range of SCP changes of E. integriceps was relatively low during diapause, and the mean SCP was the lowest in the phase of the diapause maintenance of the adults. This interpretation was compatible with that reported by Hodkova and Hodek (1997) indicating that SCP of the overwintering adults of $P$. apterus was about $-7^{\circ} \mathrm{C}$ at the onset of the pre-diapause and decreased to about $-12^{\circ} \mathrm{C}$ in the overwintering adults (January and February). Bastola and Davis (2018) also showed that the mean SCP of the overwintering adults of the redbanded stink bug, Piezodorus guildinii (Westwood) (Hem.: Pentatomidae) changed from $-8.3^{\circ} \mathrm{C}$ (in March) to $-11.0 \pm 0.2^{\circ} \mathrm{C}$ (in January). Moreover, Cira et al. (2016) reported limited changes in SCP during summer, fall, and winter among different geographical populations of Halyomorpha halys (Hem.: Pentatomidae). Elsey (1993) reported that SCP of the diapausing and non-diapausing adults of Nezara viridula (L.) (Hem.: Pentatomidae) ranged from $-10.4^{\circ} \mathrm{C}$ to $-11.7^{\circ} \mathrm{C}$. This limited range of SCP suggested that the diapausing adults of E. integriceps might employ more than one survival strategy. During the overwintering stages, the cold tolerance of those insects, which are physiologically incapable of synthesizing and accumulating cryoprotectants, is usually accompanied by the SCP depression. That is to say, the SCP expansion is the main coldtolerance strategy deployed by this group of insects (Mollaei et al., 2016). However, in the insects with the capability of cryoprotectant biosynthesis and accumulation, the SCP changes are commonly limited, and the development of cold tolerance is commonly associated with cryoprotectant accumulation and/or SCP degradation (Zachariassen, 1985; Heydari and Izadi, 2014; Sinclair et al., 2015; Ditrich et al., 2018).

The results of this study showed that the association between minimum ambient temperature and the mean SCP was not strong and straightforward. Likewise, the values for SCP of the diapausing adults of E. integriceps did not follow a direct seasonal trend. The lowest SCP was achieved in October, whereas the lowest temperature was recorded in February. The same results were released by Ditrich et al. (2018). They stated that SCP 


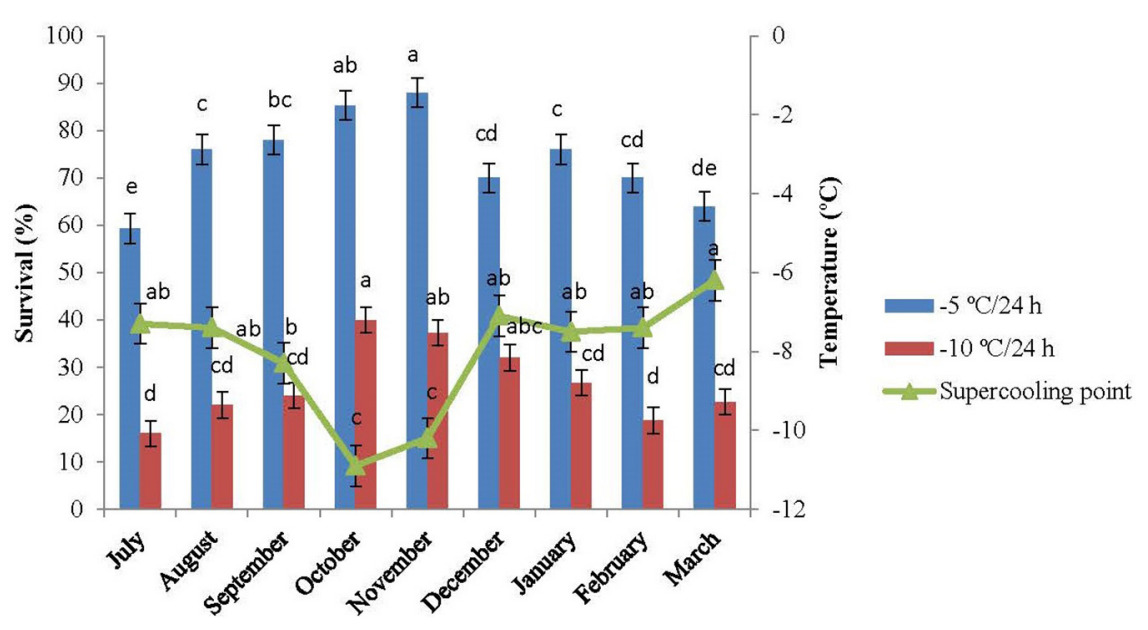

FIGURE 3 | Changes in the supercooling point and survival of Eurygaster integriceps during different months of diapause. Means \pm SE: for each month, means followed by the same letter are not significantly different $(P>0.05)$ (each experiment was carried out with six individuals each month).

of the linden bug, $P$. apterus could strongly correlate with the ambient temperature; however, there was no direct relationship between the lowest ambient temperature and SCP. Mollaei et al. (2016) also mentioned that the SCP values and the ambient temperatures did not follow the same direct seasonal trend in the overwintering larvae of Kermania pistaciella (Lep.: Tineidae). On the other hand, Ditrich and Koštál (2011) proposed a strong correlation between SCP and lower lethal temperatures among nine species of the semi-aquatic bugs (Hem.: Gerromorpha). In the current study, SCP was approximately $5^{\circ} \mathrm{C}$ lower than the minimum ambient temperature. In the research done by Ditrich et al. (2018), the SCP of $P$. apterus was about $10^{\circ} \mathrm{C}$ lower than the minimum ambient temperature.

\section{Cold-Tolerance Strategies}

When the pre-diapausing and diapausing adults of E. integriceps were exposed to $-5^{\circ} \mathrm{C}$ and $-10^{\circ} \mathrm{C} / 24 \mathrm{~h}$, survival increased with a decrease in SCP and reached the highest level in October and November with the lowest SCP. From November onward, survival decreased with an increase in SCP, the rate of which in March corresponded to that in July (Figure 3). Cold tolerance in the phase of diapause maintenance was significantly higher than that in the initiation and at the termination of the diapause. The least survival rate was observed in the initiation and at the termination phases of the diapausing adults with survival rates of 16.0 and $18.7 \%$, respectively, following the exposure to $-10^{\circ} \mathrm{C} / 24 \mathrm{~h}$. Almost no adults survived after 24 -h exposure to $-15^{\circ} \mathrm{C}$.

The increase in cold tolerance of the diapausing adults was highlighted by a remarkable decrease in the range of SCP. This finding indicated that SCP had a predictive value and could be recommended as a suitable means for the determination of the survival of the overwintering adults. This was in agreement with the results reported by Kalushkov and Nedvěd (2000) and Ditrich et al. (2018), suggesting the use of SCP as an appropriate index of cold hardiness in the overwintering adults of $P$. apterus.
One of the tactics the overwintering adults of E. integriceps exploited to survive in cold conditions was migration to higher altitudes, thus entering diapause in the aggregate populations under shelter shrubs. Besides, the results of the current work suggested seasonal cold acclimation as a further means by which the diapausing adults of $E$. integriceps reduced the lethal effects of exposure to low temperatures. This is typical of many temperate insects (Cira et al., 2016). Since the overwintering adults of E. integriceps could not survive temperatures below their SCPs, this pest was considered to be a freeze-intolerant species. The Linden Bug, P. apterus, was also reported to be a freeze-intolerant species (Kalushkov and Nedvěd, 2000; Cira et al., 2016).

\section{Seasonal Changes in Water Content and Body Mass of Adults}

The water content of the adult insects slightly varied from the beginning to the end of the diapause. High water content was recorded in three phases, i.e., initiation (July), maintenance (October-December), and termination (March). The difference in the water content of these phases of the diapause was not significant. However, the water content in December was significantly more than that in August-September and in January-February (Figure 4). In most of the insects, diapause termination is associated with an increase in water content to resume morphogenesis (Frankos and Platt, 1976; Hodek, 2003). In the current research, the water content of the diapausing adults of the Sunn pest at the diapause termination (March) increased and corresponded to that in the diapause initiation (July). In coincidence with this result, Xiao et al. (2015) found that water content in the non-diapausing pupae of Pieris melete (Lep.: Pieridae) was significantly more than that in the diapausing pupae. Besides, the changes in the water content of the diapausing pupae were almost negligible during the diapause initiation and maintenance phases but substantially increased at the diapause termination phase. Heydari and Izadi (2014) also found an appreciable difference between the 
water content of the diapausing (62\%) and the non-diapausing (80\%) larvae of the carob moth, Ectomyelois ceratoniae Zeller (Lep.: Pyralidae).

Numerous physiological and cellular survival mechanisms were exploited by insects when exposing to low temperatures, among which freeze tolerance, freeze avoidance, and cryoprotective dehydration were the most important ones (Clark et al., 2009; Sinclair et al., 2015). Cryoprotective dehydration is one of the least frequently used strategies insects deploy to adapt to cold conditions. By exploiting this tactic, insects become almost anhydrobiotic due to a decrease in their water content. This adaptation mechanism may be used by both freeze-avoiding and freeze-tolerating species, including Graphosoma lineatum (Šlachta et al., 2002), Belgica antarctica (Elnitsky et al., 2008), Megaphorura arctica (Worland et al., 2010), Cucujus clavipes puniceus (Sformo et al., 2010), Hypogastrura viatica, Folsomia quadrioculata, Oligaphorura groenlandica and M. arctica (Sørensen and Holmstrup, 2011), Dendrolimus tabulaeformis (Shao et al., 2018), and P. melete (Xiao et al., 2015), to survive cold stress via increasing osmolyte concentration. No significant differences were detected between the weights of the adults from July to December, although their weights in January and February were significantly lower than those in July (Figure 5). The pre-diapause insects generally accumulate reserves and utilize these energy sources during the metabolically depressed phase of the diapause (Hahn and Denlinger, 2011). Therefore, lowering the weight at the diapause termination phase might be attributed to the depletion of energy resources and the decrease in water content. Brent et al. (2013) found that the weight of the non-diapausing plant bug, Lygus hesperus Knight (Hem.: Miridae), was discernibly larger than that of the diapausing one.

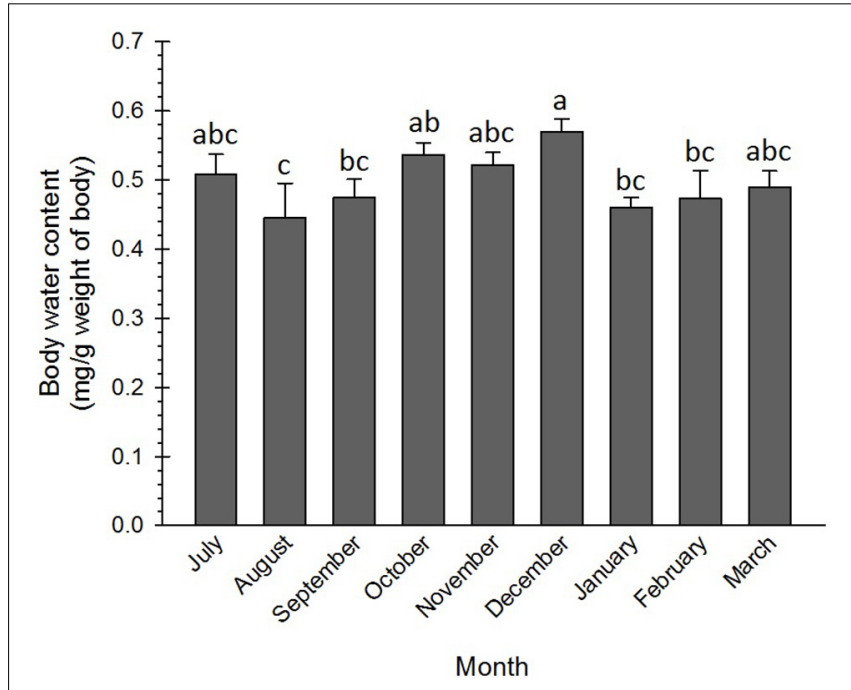

FIGURE 4 | Changes in water content of Eurygaster integriceps during different months of diapause. Means \pm SE: for each month means within a column followed by the same letter are not significantly different $(P>0.05)$ (each experiment was carried out with 6 individuals each month).

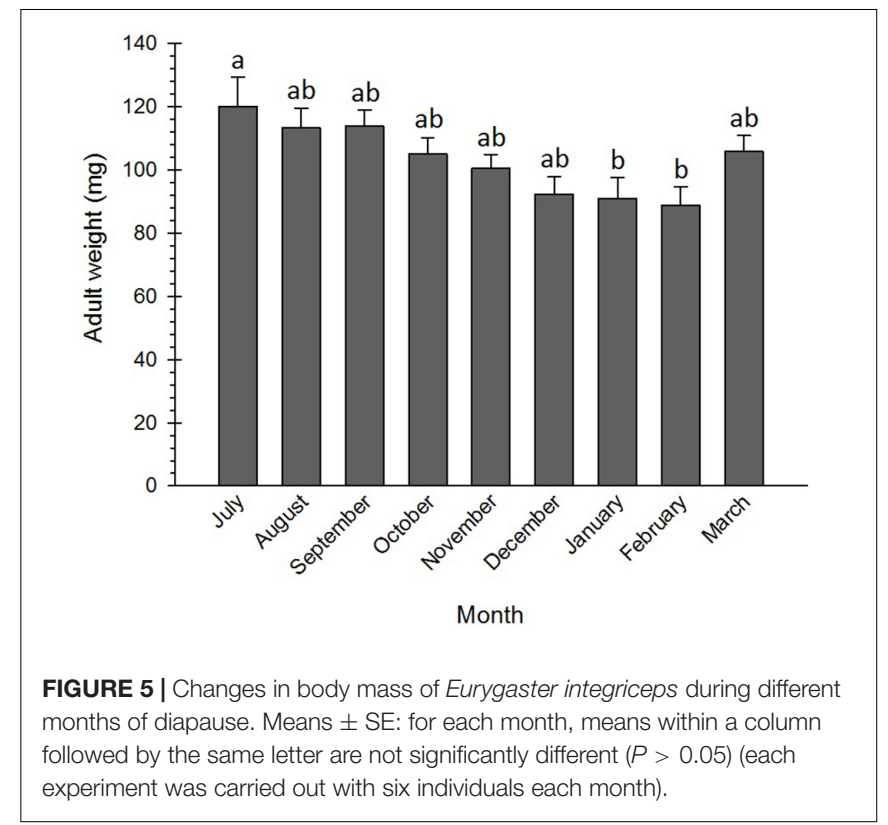

\section{Biochemical Analysis}

\section{Total Body Sugar and Glycogen and Lipid Contents}

In the initiation phase of the diapause, i.e., July, the total body sugars, forming $12.14 \mathrm{mg} / \mathrm{g}$ of the weight of the body, were at the highest level. These amounts decreased toward December and reached the lowest level in the diapause maintenance. From December onward, the total body sugars increased (Table 1). That is to say, the sugar reserves were most likely utilized during the diapause initiation and termination when the ambient temperature was almost suitable. The adult insects, however, migrated to the diapausing habitats and stayed there in a dormant state. The changes in the glycogen and lipid contents were inversely proportional to those in the total sugar content (Table 1). In the diapause initiation, glycogen and lipid contents ( 8.68 and $4.38 \mathrm{mg} / \mathrm{g}$ of the weight of the body, respectively) were at the lowest level and increased with the diapause development; from November onward, the contents reached the highest level. These results showed that the overwintering adults of E. integriceps altered their metabolic energy reserves during different phases of the diapause. In accordance with this result, Amiri and Bandani (2013) demonstrated that the energy reserves of the Sunn pest varied from the diapause initiation to the diapause maintenance. Based on the findings of the current study, the overwintering adults of E. integriceps mostly relied on sugars as the main energy reserve in the diapause initiation and switched to another fuel source (lipids) in the diapause maintenance when metabolism was fully repressed. Amiri and Bandani (2013) also reported that the diapausing adults of the Sunn pest accumulated lipids for their metabolic needs during the diapause maintenance and termination. Most of the insects generally suppress their metabolism during overwintering. Therefore, before the diapause initiation, to survive in the suppressed metabolic conditions, insects must equip themselves physiologically. Moreover, to provide the energetic demands of the post-diapause development 
and the reproduction or to perform metabolically expensive functions, such as migration, overwintering insects must manage their energy resources during diapause maintenance (Hahn and Denlinger, 2011; Tan et al., 2017; Sinclair and Marshall, 2018). Lipids and glycogen are the two main sources satisfying the energy demands of the overwintering insect (Arrese and Soulages, 2010; Sinclair and Marshall, 2018). An increase in glycogen content and a decrease in total body sugar content indicate an interconversion of these two carbohydrates and diapause development. Also, the increased glycogen content can provide the necessary cryoprotectants and energy reserves. Overall, the deceased sugar content might denote that the adults were consuming sugar as the diapause went on, and the increased glycogen and lipid contents could indicate that these two forms of nutrients were stored in the diapausing adults. Moreover, the increased glycogen and lipid contents might be derived from the consumed sugar. In the diapausing larvae of Dendrolimus tabulaeformis (Lep.: Lasiocampidae), the glycogen content reached its peak in November and then decreased (Shao et al., 2018). Lu et al. (2014) suggested that increased metabolites might be employed by the diapause-destined pupae of the cotton bollworm, Helicoverpa armigera (Hübner) (Lep.: Noctuidae), as an energy source, metabolic intermediates, and cryoprotectants. In the current study, glycogen content increased during the diapause termination, while the changes in the total lipid content were not significant (Table 1). However, in most insects, the energy levels of the metabolic activities rapidly increase with diapause termination to meet the energy demands for the postdiapause growth and reproduction (Lu et al., 2014; Sinclair and Marshall, 2018). Batz and Armbruster (2018) observed that the embryonic diapause of the Asian tiger mosquito, Aedes albopictus (Skuse) (Dip.: Culicidae), was associated with increased energy storage (lipids) and with lipogenesis. Shao et al. (2018) documented that the lipid content of the diapausing larvae of $D$. tabulaeformis gradually decreased during the diapause initiation, remained stable in the diapause maintenance, and reached amounts comparable to those observed in September at the diapause termination. Zhang et al. (2019) showed that the overwintering females of Culex pipiens pallens (L.) (Dip: Culicidae) accumulated more lipids during the diapause initiation and maintenance than during the non-diapausing phase. Employing lipids as a source of energy during diapause was also found in some other insects (Han et al., 2008; Behroozi et al., 2012; Bemani et al., 2012; Heydari and Izadi, 2014).

\section{Low-Molecular-Weight Carbohydrates (LMWC)}

In this research, five potential cryoprotectants, i.e., trehalose, glycerol, sorbitol, myo-inositol, and glucose, were detected in the overwintering adults of E. integriceps from July to March. Out of these five LMWCs, glucose, glycerol, and trehalose were found to be the most prominent cryoprotectants in the overwintering adults. The amounts of these carbohydrates were at the lowest levels in the diapause initiation, reached the highest levels in the diapause maintenance, and decreased at the diapause termination (Table 2). Insects commonly synthesize and accumulate cryoprotectants during overwintering. An increase in the concentration of these metabolites results in elevated hemolymph viscosity (Toxopeus and Sinclair, 2018; Sinclair and Marshall, 2018; Toxopeus et al., 2019). Likewise, Shao et al. (2018) studied the changes in the concentration of trehalose, glucose, and glycerolin in the overwintering larvae of D. tabulaeformis. They concluded that trehalose was the main cryoprotectant, whose level reached the highest in November. However, glycerol content remained unchanged during the diapause maintenance, though it substantially rose in May. Glucose content was at the maximum level in January and then gradually decreased. The overwintering nymphs of the wolf spider Pardosa astrigera (Araneae: Lycosidae) accumulated a high level of glycerol and a small amount of myo-inositol (Tanaka and Ito, 2015). In the overwintering nymphs and the adults of the bush tick, Haemaphysalis longicornis (Acari: Ixodidae), the glycerol content showed a marked elevation (Yu et al., 2014).

Interestingly, the SCP reducing trend and the cold-hardiness development patterns, observed during the course of the diapause maintenance of E. integriceps, were consistent with the tendency found in these insects for increasing their cryoprotectant levels. Most of the diapausing insects enhanced their SCP and cold tolerance via regulating physiological-biochemical processes, thus resulting in cryoprotectant synthesis and accumulation. In the current research, the least SCP and the maximum cold

TABLE 1 | Chemical content of overwintering adults of Eurygaster integriceps $(n=6)$ in 2015-2016.

\begin{tabular}{|c|c|c|c|c|}
\hline Month & \multicolumn{4}{|c|}{ Chemical contents (mg/g body weight) } \\
\hline July & $12.14 \pm 0.48^{\mathrm{a}}$ & $8.68 \pm 0.14^{c}$ & $4.38 \pm 0.23^{\mathrm{cd}}$ & $2.16 \pm 0.04^{b c}$ \\
\hline August & $6.23 \pm 0.22^{c}$ & $8.63 \pm 0.31^{c}$ & $4.24 \pm 0.13^{d}$ & $2.09 \pm 0.10^{b c}$ \\
\hline September & $3.09 \pm 0.08^{e}$ & $9.08 \pm 0.22^{b c}$ & $4.43 \pm 0.04^{\mathrm{cd}}$ & $1.86 \pm 0.05^{c}$ \\
\hline October & $3.69 \pm 0.07^{\mathrm{de}}$ & $10.84 \pm 0.18^{\mathrm{a}}$ & $4.77 \pm 0.03^{\mathrm{c}}$ & $1.73 \pm 0.07^{\mathrm{c}}$ \\
\hline January & $4.29 \pm 0.07^{d}$ & $11.05 \pm 0.27^{\mathrm{a}}$ & $5.63 \pm 0.12^{a}$ & $2.60 \pm 0.13^{a}$ \\
\hline February & $5.81 \pm 0.01^{\mathrm{C}}$ & $11.19 \pm 0.38^{a}$ & $5.78 \pm 0.08^{a}$ & $2.70 \pm 0.05^{a}$ \\
\hline March & $8.60 \pm 0.07^{b}$ & $10.73 \pm 0.28^{\mathrm{a}}$ & $4.83 \pm 0.11^{\mathrm{bc}}$ & $2.73 \pm 0.08^{a}$ \\
\hline
\end{tabular}

Means \pm SE: means within a column followed by the same letter are not significantly different $(P>0.05)$. 
TABLE 2 | Carbohydrate contents of overwintering adults of Eurygaster integriceps in 2015-2016.

\begin{tabular}{|c|c|c|c|c|c|}
\hline Time & Trehalose & Glycerol & Sorbitol & Myo-inositol & Glucose \\
\hline July & $0.24 \pm 0.01^{\mathrm{c}}$ & $0.63 \pm 0.00^{f}$ & $0.01 \pm 0.00^{d}$ & $0.09 \pm 0.00^{c}$ & $0.50 \pm 0.01^{c}$ \\
\hline August & $0.24 \pm 0.00^{c}$ & $0.63 \pm 0.01^{f}$ & $0.02 \pm 0.00^{\mathrm{cd}}$ & $0.11 \pm 0.00^{b c}$ & $0.38 \pm 0.01^{c}$ \\
\hline September & $0.26 \pm 0.00^{c}$ & $0.75 \pm 0.00^{\mathrm{e}}$ & $0.02 \pm 0.00^{\mathrm{cd}}$ & $0.11 \pm 0.00^{b c}$ & $0.43 \pm 0.01^{\circ}$ \\
\hline October & $0.42 \pm 0.00^{b}$ & $0.89 \pm 0.01^{d}$ & $0.04 \pm 0.00^{a b}$ & $0.13 \pm 0.01^{b}$ & $0.73 \pm 0.02$ \\
\hline November & $0.46 \pm 0.00^{a}$ & $0.92 \pm 0.00^{\mathrm{cd}}$ & $0.05 \pm 0.00^{a}$ & $0.18 \pm 0.00^{a}$ & $0.88 \pm 0.03^{b}$ \\
\hline December & $0.47 \pm 0.00^{a}$ & $0.94 \pm 0.00^{b c}$ & $0.05 \pm 0.00^{\mathrm{a}}$ & $0.17 \pm 0.00^{a}$ & $1.26 \pm 0.01^{a}$ \\
\hline January & $0.48 \pm 0.01^{a}$ & $1.24 \pm 0.01^{a}$ & $0.05 \pm 0.00^{a}$ & $0.18 \pm 0.00^{a}$ & $1.22 \pm 0.01^{a}$ \\
\hline February & $0.41 \pm 0.01^{b}$ & $1.26 \pm 0.01^{a}$ & $0.04 \pm 0.00^{a b}$ & $0.16 \pm 0.00^{a}$ & $0.92 \pm 0.01^{b}$ \\
\hline March & $0.25 \pm 0.01^{\mathrm{c}}$ & $0.97 \pm 0.00^{b}$ & $0.03 \pm 0.00^{b c}$ & $0.12 \pm 0.00^{b}$ & $0.74 \pm 0.02^{c}$ \\
\hline
\end{tabular}

Means \pm SE: means within a column followed by the same letter are not significantly different $(P>0.05)$.

hardiness in the diapause maintenance corresponded to the highest amounts of glucose, glycerol, and trehalose. That is, the diapausing adults employed these metabolites as cryoprotectants to enhance their cold tolerance. The diapausing larvae of D. tabulaeformis regulated their SCP capacity and cold tolerance by the accumulation of trehalose and glucose (Shao et al., 2018). Insects living in the areas having severe ambient temperature during winter (temperate region) resort to either freeze-tolerance or freeze-intolerance mechanisms to survive in cold conditions (Storey and Storey, 2004; Lee, 2010; Sinclair et al., 2015). Similar to many other freeze-intolerant species, the diapausing adults of E. integriceps increased their SCP and cold hardiness via the accumulation of antifreeze cryoprotectants, such as glycerol, trehalose, and glucose, having colligative effects on their internal body fluids. Ishiguro et al. (2007) documented that the enhancement of cold hardiness in the overwintering larvae of rice stem borer, Chilo suppressalis (Walker) (Lep.: Crambidae) was associated with the elevation of glycerol level. Kalushkov and Nedverd (2000) found a correlation between SCP and the cold hardiness of the diapausing adults of $P$. apterus. However, the results of the study done by Rozsypal et al. (2018) did not support the current findings. They found that increased metabolite concentration had no substantial effect on the cold hardiness of the bean bug, Riptortus pedestris (Fabricius) (Hem.: Alydidae).

The authors of the current study observed a direct correlation between the changes in glycogen content and those in LMWCs and diapause development. This finding was contrary to what they previously observed in another study, where the glycogen and LMWC contents did not follow the same increasing/decreasing trend, and glycogen was subsequently regarded as a source of cryoprotectants (Bemani et al., 2012; Heydari and Izadi, 2014; Khanmohamadi et al., 2016). The results of the present study indicated that there was a significant correlation among developing diapause, accumulating cryoprotectants, and increasing cold tolerance. That is to say, the diapause maintenance in the overwintering adults of E. integriceps was tightly associated with the enhancement of cold tolerance.

\section{Changes in the Enzyme Activity}

In this study, the activities of two enzymes, i.e., $\alpha$-amylase and protease, were investigated during the diapause of the adult

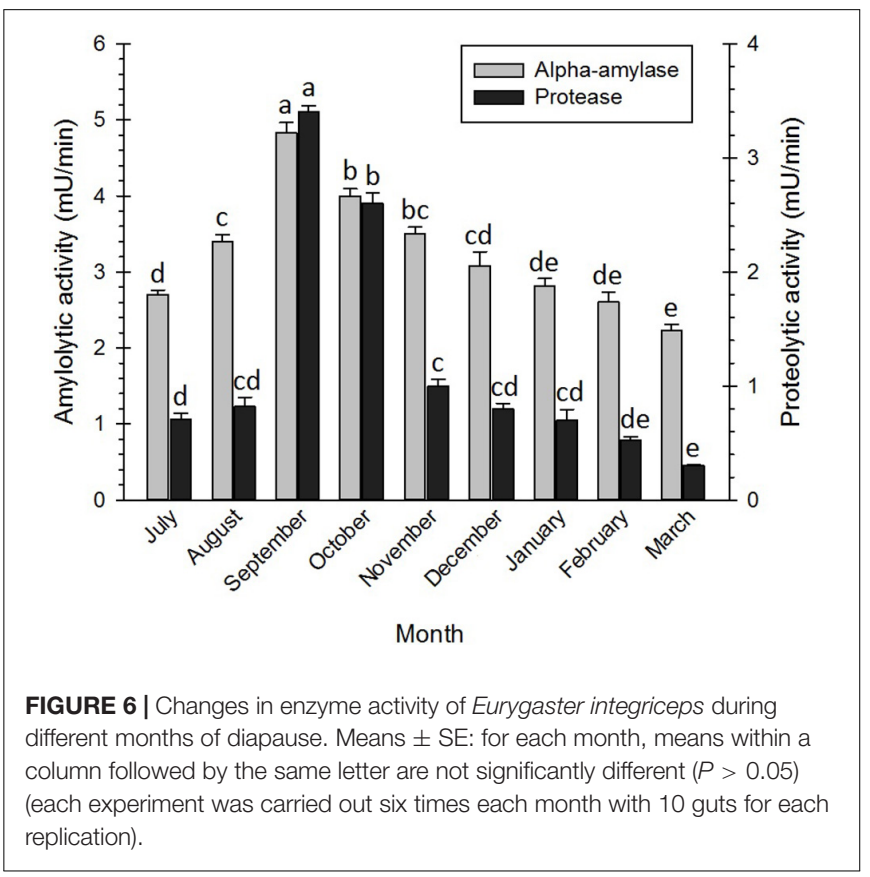

bugs. The results (Figure 6) showed that diapauses development was closely associated with enzyme activities. The activities of $\alpha$-amylases in the initiation and at the termination of the diapause were generally higher than those of proteases in the mentioned phases. However, the activities of the enzymes increased with the diapause development and reached the highest levels in September. From September onward, the activities of the enzymes decreased and reached the lowest levels at the diapause termination (February-March). Similarly, Dmochowska et al. (2013) documented that the amylase activities significantly reduced at the end of the diapause of the red mason bee, Osmia rufa (Linnaeus) (Hym.: Megachilidae). Abraham et al. (1992) also hypothesized that the amylase activities in the diapausing strain of the silkworm, Bombyx mori L, were negligible, whereas the given activities substantially increased in the non-diapausing strain of the silkworm. Likewise, Shappirio (1974) reported higher activities in all studied enzyme systems of the diapausing pupae of B. mori. In E. plotnikovi Nikol'skaya (Hym.: Eurytomidae), however, the activities of $\alpha$-amylase 
markedly differed in the diapausing and the non-diapausing larvae (Mohammadzadeh et al., 2017). In another study, it was demonstrated that the genes encoding the protease of Leptinotarsa decemlineata (Say) (Col.: Chrysomelidae) were down-regulated in the diapausing adults and relatively upregulated in the non-diapausing adults (Yocum et al., 2009). In September, the adult bugs migrated from the temporal shelters to the overwintering habitats in the nearby mountains and hills. This behavior coincided with a decrease in total sugar content, an increase in LMWCs, glycogen, lipids, and proteins, and enhancement of the enzyme activities. By studying the obtained figures of the research, the authors detected that protease enzymes were far more active than amylase enzymes, suggesting that amino acids (e.g., proline, arginine, and serine) were significantly correlated with the cold tolerance of the diapausing adults, compared with sugars. Free amino acids could also contribute to an increase in cold hardiness by growing osmolality. They could also function as stabilizers for protecting cell membranes from degradation upon exposure to cold conditions (Goto et al., 2001; Bale et al., 2002; Feng et al., 2016; Koštál et al., 2016).

Glycosyl hydrolase enzymes, or $\alpha$-amylases, are the main group of digestive enzymes that break down $\alpha$-1,4-glycosidic linkages of a polysaccharide (e.g., starch and glycogen), resulting in, for example, maltose as one of the end products. As a substrate of $\alpha$-glucosidases, maltose is, in turn, hydrolyzed into glucose (Da Lage, 2018). The reduction in total body sugars in the diapause initiation of E. integriceps might be attributed to its conversion into LMWCs and glycogen under the up-regulation of the catalytic activities of amylase enzymes. The hydrolysis of the peptide bonds in the polypeptide chain of proteins is catalyzed by a class of enzymes, i.e., protease or peptidase. These enzymes often perform in a cascade pathway (Kanost and Clem, 2012). In the current study, the activities of the protease enzymes reached the highest level in September, gradually decreased, and finally reached the lowest level at the diapause termination. Down-regulation of the digestive enzymes during the diapause

\section{REFERENCES}

Abraham, E. G., Nagaraju, J., and Datta, R. K. (1992). Biochemical studies of amylases in the silkworm, Bombyx mori L.: comparative analysis in diapausing and nondiapausing strains. Insect Biochem. Mol. Biol. 22, 867-873. doi: 10.1016/ 0965-1748(92)90113-S

Amiri, A., and Bandani, A. R. (2013). Comparison of energy reserves in prediapause and diapausing adult sunn pest, Eurygaster integriceps puton (Hemiptera: Scutelleridae). J. Agric. Sci. Technol. 15, 435-444.

Arrese, E. L., and Soulages, J. L. (2010). Insect fat body: energy, metabolism, and regulation. Annu. Rev. Entomol. 55, 207-225. doi: 10.1146/annurev-ento112408-085356.INSECT

Baghdadi, A. (2007). Strategy of freeze tolerance in adult of sunn pest bug (Eurygaster integriceps Put.). Commun. Agric. Appl. Biol. Sci. 72, 469-473.

Baghdadi, A., Saeid, M., Azra, R., and Abbas, A. (2001). Cold hardiness strategies and it's seasonal variation in sunn pest (Eurygaster integriceps Put.). Appl. Entomol. Phytopathol. 69, 51-60.

Bale, J. S., Gerday, C., Parker, A., Marahiel, M. A., Shanks, I. A., Davies, P. L., et al. (2002). Insects and low temperatures: from molecular biology to distributions and abundance. Philos. Trans. R. Soc. B Biol. Sci. 357, 849-862. doi: 10.1098/ rstb.2002.1074 maintenance could be attributed to the metabolic suppression during this phase of the diapause.

\section{CONCLUSION}

The results of this study suggest that the diapausing adults of E. integriceps are freeze-intolerant species. This pest survived in very cold conditions of the diapause maintenance phase by accumulating LMWC cryoprotectants and by reducing SCP. The results of the current study can be employed to predict a model for the immigration of overwintering adults into the fields.

\section{DATA AVAILABILITY STATEMENT}

The datasets generated for this study are available on reasonable request to the corresponding author.

\section{AUTHOR CONTRIBUTIONS}

$\mathrm{HH}$ and $\mathrm{HI}$ conceived and designed the research and conducted the experiments. HI and MM contributed to the analytical tools and to the analysis of the data. HI wrote the manuscript.

\section{FUNDING}

This research was supported by Vali-e-Asr University of Rafsanjan (Rafsanjan, Iran).

\section{ACKNOWLEDGMENTS}

The authors wish to thank the Deputy of Research, Vali-e-Asr University of Rafsanjan for a grant to HI.

Bastola, A., and Davis, J. A. (2018). Cold tolerance and supercooling capacity of the redbanded stink bug (Hemiptera: Pentatomidae). Environ. Entomol. 47, 133-139. doi: 10.1093/ee/nvx177

Batz, Z. A., and Armbruster, P. A. (2018). Diapause-associated changes in the lipid and metabolite profiles of the Asian tiger mosquito, Aedes albopictus. J. Exp. Biol. 221:jeb189480. doi: 10.1242/jeb.189480

Behroozi, E., Izadi, H., Samih, M. A. A., and Moharamipour, S. (2012). Physiological strategy in overwintering larvae of pistachio white leaf borer, Ocneria terebinthina Strg. (Lepidoptera: Lymantriidae) in Rafsanjan, Iran. Ital. J. Zool. 79, 44-49. doi: 10.1080/11250003.2011.59 2152

Bemani, M., Izadi, H., Mahdian, K., Khani, A., and Amin Samih, M. (2012). Study on the physiology of diapause, cold hardiness and supercooling point of overwintering pupae of the pistachio fruit hull borer, Arimania comaroffi. J. Insect Physiol. 58, 897-902. doi: 10.1016/j.jinsphys.2012. 04.003

Bernfeld, P. (1955). Amylases, $\alpha$ and $\beta$. Meth. Enzym. 1, 149-158.

Borzoui, E., Naseri, B., and Rahimi Namin, F. (2015). Different diets affecting biology and digestive physiology of the Khapra beetle, Trogoderma granarium Everts (Coleoptera: Dermestidae). J. Stored Prod. Res. 62, 1-7. doi: 10.1016/j. jspr.2015.03.003 
Brent, C. S., Klok, C. J., and Naranjo, S. E. (2013). Effect of diapause status and gender on activity, metabolism, and starvation resistance in the plant bug Lygus hesperus. Entomol. Exp. Appl. 148, 152-160. doi: 10.1111/eea.12081

Cira, T. M., Koch, R. L., Burkness, E. C., Hutchison, W. D., and Venette, R. C. (2018). Effects of diapause on Halyomorpha halys (Hemiptera: Pentatomidae) cold tolerance. Environ. Entomol. 47, 997-1004. doi: 10.1093/ee/nvy064

Cira, T. M., Venette, R. C., Aigner, J., Kuhar, T., Mullins, D. E., Gabbert, S. E., et al. (2016). Cold tolerance of Halyomorpha halys (Hemiptera: Pentatomidae) across geographic and temporal scales. Environ. Entomol. 45, 484-491. doi: 10.1093/ee/nvv220

Clark, M. S., Thorne, M. A. S., Purać, J., Burns, G., Hillyard, G., Popović, ŽD., et al. (2009). Surviving the cold: molecular analyses of insect cryoprotective dehydration in the Arctic springtail Megaphorura arctica (Tullberg). BMC Genomics 10:328. doi: 10.1186/1471-2164-10-328

Costanzo, J. P., and Lee, R. E. (2013). Avoidance and tolerance of freezing in ectothermic vertebrates. J. Exp. Biol. 216, 1961-1967. doi: 10.1242/jeb.070268

Da Lage, J.-L. (2018). The amylases of insects. Int. J. Insect Sci. 10:117954331880478. doi: 10.1177/1179543318804783

Davari, A., and Parker, B. L. (2018). A review of research on Sunn Pest \{Eurygaster integriceps Puton (Hemiptera: Scutelleridae)\} management published 20042016. J. Asia Pac. Entomol. 21, 352-360. doi: 10.1016/j.aspen.2018.01.016

Denlinger, D. L. (1991). "Relationship between cold hardiness and diapause," in Insects at Low Temperature, eds R. E. Lee Jr. and D. L. Denlinger (New York, NY: Chapman and Hall), 174-198. doi: 10.1007/978-1-4757-0190-6_8

Diniz, D. F. A., De Albuquerque, C. M. R., Oliva, L. O., De Melo-Santos, M. A. V., and Ayres, C. F. J. (2017). Diapause and quiescence: dormancy mechanisms that contribute to the geographical expansion of mosquitoes and their evolutionary success. Parasites Vectors 10:310. doi: 10.1186/s13071-017-2235-0

Ditrich, T. (2018). Supercooling point is an individually fixed metric of cold tolerance in Pyrrhocoris apterus. J. Therm. Biol. 74, 208-213. doi: 10.1016/j. jtherbio.2018.04.004

Ditrich, T., Janda, V., Vaněčková, H., and Doležel, D. (2018). Climatic variation of supercooling point in the linden bugPyrrhocoris apterus (Heteroptera: Pyrrhocoridae). Insects 9:144. doi: 10.3390/insects9040144

Ditrich, T., and Koštál, V. (2011). Comparative analysis of overwintering physiology in nine species of semi-aquatic bugs (Heteroptera: Gerromorpha). Physiol. Entomol. 36, 261-270. doi: 10.1111/j.1365-3032.2011.00794.x

Dmochowska, K., Giejdasz, K., Fliszkiewicz, M., and Żółtowska, K. (2013). Prolonged postdiapause: influence on some indicators of carbohydrate and lipid metabolism of the red mason bee, Osmia rufa. J. Insect Sci. 13, 1-12. doi: $10.1673 / 031.013 .7701$

Duman, J. G. (2015). Animal ice-binding (antifreeze) proteins and glycolipids: an overview with emphasis on physiological function. J. Exp. Biol. 218, 1846-1855. doi: $10.1242 /$ jeb.116905

Elnitsky, M. A., Hayward, S. A. L., Rinehart, J. P., Denlinger, D. L., and Lee, R. E. (2008). Cryoprotective dehydration and the resistance to inoculative freezing in the Antarctic midge, Belgica antarctica. J. Exp. Biol. 211, 524-530. doi: $10.1242 /$ jeb. 011874

Elpidina, E. N., Vinokurov, K. S., Gromenko, V. A., Rudenskaya, Y. A., Dunaevsky, Y. E., and Zhuzhikov, D. P. (2001). Compartmentalization of proteinases and amylases in Nauphoeta cinerea midgut. Arch. Insect Biochem. Physiol. 48, 206-216. doi: 10.1002/arch.10000

Elsey, K. D. (1993). Cold tolerance of the southern green stink bug (Heteroptera: Pentatomidae). Environ. Entomol. 22, 567-570. doi: 10.1093/ee/22.3.567

Feng, Y., Xu, L., Li, W., Xu, Z., Cao, M., Wang, J., et al. (2016). Seasonal changes in supercooling capacity and major cryoprotectants of overwintering Asian longhorned beetle (Anoplophora glabripennis) larvae. Agric. For. Entomol. 18, 302-312. doi: 10.1111/afe.12162

Feng, Y., Zhang, L., Li, W., Yang, X., and Zong, S. (2018). Cold hardiness of overwintering larvae of Sphenoptera sp. (Coleoptera: Buprestidae) in Western China. J. Econ. Entomol. 111, 247-251. doi: 10.1093/jee/tox304

Frankos, V. H., and Platt, A. P. (1976). Glycerol accumulation and water content in larvae of Limenitis archippus: their importance to winter survival. J. Insect Physiol. 22, 623-628. doi: 10.1016/0022-1910(76)90225-0

Fuller, B. J. (2004). Cryoprotectants: the essential antifreezes to protect life in the frozen state. Cryo Lett. 25, 375-388.

Gatehouse, A. M. R., Norton, E., Davison, G. M., Babbé, S. M., Newell, C. A., and Gatehouse, J. A. (1999). Digestive proteolytic activity in larvae of tomato moth,
Lacanobia oleracea; effects of plant protease inhibitors in vitro and in vivo. J. Insect Physiol. 45, 545-558. doi: 10.1016/S0022-1910(98)00161-9

Goto, M., Sekine, Y., Outa, H., Hujikura, M., and Suzuki, K. (2001). Relationships between cold hardiness and diapause, and between glycerol and free amino acid contents in overwintering larvae of the oriental corn borer, Ostrinia furnacalis. J. Insect Physiol. 47, 157-165. doi: 10.1016/S0022-1910(00)00099-8

Hahn, D. A., and Denlinger, D. L. (2011). Energetics of insect diapause. Annu. Rev. Entomol. 56, 103-121. doi: 10.1146/annurev-ento-112408-085504

Han, R.-D., Gan, Y.-L., Kong, X.-H., and Ge, F. (2008). Physiological and endocrine differences between diapausing and non-diapausing larvae of the pine caterpillar. Zool. Stud. 47, 1-13.

Hand, S. C., Denlinger, D. L., Podrabsky, J. E., and Roy, R. (2016). Mechanisms of animal diapause: recent developments from nematodes, crustaceans, insects, and fish. Am. J. Physiol. Integr. Comp. Physiol. 310, R1193-R1211. doi: 10.1152/ ajpregu.00250.2015

Heydari, M., and Izadi, H. (2014). Effects of seasonal acclimation on cold tolerance and biochemical status of the carob moth, Ectomyelois ceratoniae Zeller, last instar larvae. Bull. Entomol. Res. 104, 592-600. doi: 10.1017/ S0007485314000364

Hodek, I. (2003). Role of water and moisture in diapause development (A review). Eur. J. Entomol. 100, 223-232. doi: 10.14411/eje.2003.037

Hodkova, M., and Hodek, I. (1997). Temperature regulation of supercooling and gut nucleation in relation to diapause of Pyrrhocoris apterus (L.) (Heteroptera). Cryobiology 34, 70-79. doi: 10.1006/cryo.1996.1985

Iranipour, S., Pakdel, A. K., and Radjabi, G. (2010). Life history parameters of the sunn pest, Eurygaster integriceps, held at four constant temperatures. J. Insect Sci. 10, 1-9. doi: 10.1673/031.010.10601

Ishiguro, S., Li, Y., Nakano, K., Tsumuki, H., and Goto, M. (2007). Seasonal changes in glycerol content and cold hardiness in two ecotypes of the rice stem borer, Chilo suppressalis, exposed to the environment in the Shonai district, Japan. J. Insect Physiol. 53, 392-397. doi: 10.1016/j.jinsphys.2006.12.014

Izadi, H., Mohammadzadeh, M., and Mehrabian, M. (2019). Changes in biochemical contents and survival rates of two stored product moths under different thermal regimes. J. Therm. Biol. 80, 7-15. doi: 10.1016/j.jtherbio.2018. 12.022

Jaworski, T., and Hilszczański, J. (2014). The effect of temperature and humidity changes on insects development their impact on forest ecosystems in the expected climate change. For. Res. Pap. 74, 345-355. doi: 10.2478/frp-20130033

Kalushkov, P., and Nedvěd, O. (2000). Cold hardiness of Pyrrhocoris apterus (Heteroptera: Pyrrhocoridae) from central and southern Europe. Eur. J.Entomol. 97, 149-153.

Kanost, M. R., and Clem, R. J. (2012). “Insect proteases," in Insect Molecular Biology and Biochemistry, ed. I. L. Gilbert (San Diego, CA: Academic Press), 346-364. doi: 10.1016/B978-0-12-384747-8.10010-8

Khanmohamadi, F., Khajehali, J., and Izadi, H. (2016). Diapause and cold hardiness of the almond wasp, Eurytoma amygdali (Hymenoptera: Eurytomidae), two independent phenomena. J. Econ. Entomol. 109, 1646-1650. doi: 10.1093/jee/ tow150

Koštál, V. (2006). Eco-physiological phases of insect diapause. J. Insect Physiol. 52, 113-127. doi: 10.1016/j.jinsphys.2005.09.008

Koštál, V., Korbelová, J., Poupardin, R., Moos, M., and Šimek, P. (2016). Arginine and proline applied as food additives stimulate high freeze tolerance in larvae of Drosophila melanogaster. J. Exp. Biol. 219, 2358-2367. doi: 10.1242/jeb.14 2158

Košál, V., and Šimek, P. (2000). Overwintering strategy in Pyrrhocoris apterus (Heteroptera): the relations between life-cycle, chill tolerance and physiological adjustments. J. Insect Physiol. 46, 1321-1329. doi: 10.1016/S0022-1910(00) 00056-1

Lee, R. E. (2010). “A primer on insect cold tolerance," in Low Temperature Biology of Insects, eds D. L. Denlinger and R. E. Lee Jr. (Cambridge: Cambridge University Press), 3-34.

Lee, R. E., Lee, R. E. Jr., and Lee, R. E. (1991). "Principles of insect low temperature tolerance," in Insects at Low Temperature, eds R. E. Lee Jr. and D. L. Denlinger (New York, NY: Chapman and Hall), 17-46. doi: 10.1007/978-1-47570190-6_2

Lehmann, P., Lyytinen, A., Sinisalo, T., and Lindström, L. (2012). Population dependent effects of photoperiod on diapause related physiological traits in 
an invasive beetle (Leptinotarsa decemlineata). J. Insect Physiol. 58, 1146-1158. doi: 10.1016/j.jinsphys.2012.06.003

Li, N. G. (2012). Relationships between cold hardiness, and ice nucleating activity, glycerol and protein contents in the hemolymph of caterpillars, Aporia crataegi L. Cryo Lett. 33, 135-143.

Lu, Y. X., Zhang, Q., and Xu, W. H. (2014). Global metabolomic analyses of the hemolymph and brain during the initiation, maintenance, and termination of pupal diapause in the cotton bollworm, Helicoverpa armigera. PLoS One 9:e99948. doi: 10.1371/journal.pone.0099948

Milonas, P. G. (1999). Cold hardiness in diapause and non-diapause larvae of the summer fruit tortrix. Adoxophyes orana (Lepidoptera: Tortricidae). Eur. J. Entomol. 96, 183-187.

Mohammadzadeh, M., Borzoui, E., and Izadi, H. (2017). Physiological and biochemical differences in diapausing and nondiapausing larvae of Eurytoma plotnikovi (Hymenoptera: Eurytomidae). Environ. Entomol. 46, 1424-1431. doi: $10.1093 /$ ee/nvx128

Mohammadzadeh, M., and Izadi, H. (2016). Enzyme activity, cold hardiness, and supercooling point in developmental stages of Acrosternum arabicum (Hemiptera: Pentatomidae). J. Insect Sci. 16, 1-6. doi: 10.1093/jisesa/iew045

Mohammadzadeh, M., and Izadi, H. (2018a). Cold acclimation of Trogoderma granarium everts is tightly linked to regulation of enzyme activity, energy content, and ion concentration. Front. Physiol. 9:1427. doi: 10.3389/fphys.2018. 01427

Mohammadzadeh, M., and Izadi, H. (2018b). Different diets affecting biology, physiology and cold tolerance of Trogoderma granarium everts (Coleoptera: Dermestidae). J. Stored Prod. Res. 76, 58-65. doi: 10.1016/j.jspr.2017.12.008

Mollaei, M., Izadi, H., Šimek, P., and Koštál, V. (2016). Overwintering biology and limits of cold tolerance in larvae of pistachio twig borer, Kermania pistaciella. Bull. Entomol. Res. 106, 538-545. doi: 10.1017/S0007485316000237

Nation, J. L. Sr. (2015). Insect Physiology and Biochemistry. Boca Raton, FL: CRC Press.

Parker, B. L., Amir-Maafi, M., Skinner, M., Kim, J. S., and El Bouhssini, M. (2011). Distribution of Sunn pest, Eurygaster integriceps Puton (Hemiptera: Scutelleridae), in overwintering sites. J. Asia. Pac. Entomol. 14, 83-88. doi: 10.1016/j.aspen.2010.10.005

Poelchau, M. F., Reynolds, J. A., Elsik, C. G., Denlinger, D. L., and Armbruster, P. A. (2013). Deep sequencing reveals complex mechanisms of diapause preparation in the invasive mosquito, Aedes albopictus. Proc. R. Soc. B Biol. Sci 280:20130143. doi: 10.1098/rspb.2013.0143

Régničre, J., St-Amant, R., and Duval, P. (2012). Predicting insect distributions under climate change from physiological responses: Spruce budworm as an example. Biol. Invasions 14, 1571-1586. doi: 10.1007/s10530-010-9918-1

Roncalli, V., Sommer, S. A., Cieslak, M. C., Clarke, C., Hopcroft, R. R., and Lenz, P. H. (2018). Physiological characterization of the emergence from diapause: a transcriptomics approach. Sci. Rep. 8:12577. doi: 10.1038/s41598-018-30873-0

Rozsypal, J., Moos, M., and Goto, S. G. (2018). Cold acclimation increases cold tolerance independently of diapause programing in the bean bug, Riptortus pedestris. Bull. Entomol. Res. 108, 487-493. doi: 10.1017/S0007485317001006

Sformo, T., Walters, K., Jeannet, K., Wowk, B., Fahy, G. M., Barnes, B. M., et al. (2010). Deep supercooling, vitrification and limited survival to $-100 \mathrm{C}$ in the Alaskan beetle Cucujus clavipes puniceus (Coleoptera: Cucujidae) larvae. J. Exp. Biol. 213, 502-509. doi: 10.1242/jeb.035758

Shao, Y., Feng, Y., Tian, B., Wang, T., He, Y., and Zong, S. (2018). Cold hardiness of larvae of Dendrolimus tabulaeformis (Lepidoptera: Lasiocampidae) at different stages during the overwintering period. Eur. J. Entomol. 115, 198-207. doi: 10.14411/eje.2018.018

Shappirio, D. G. (1974). Comparative studies of oxidative enzyme systems in epidermis and fat body of diapausing and non-diapausing silkmoths. J. Insect Physiol. 20, 291-300. doi: 10.1016/0022-1910(74)90061-4

Sinclair, B. J. (1999). Insect cold tolerance: How many kinds of frozen? Eur. J. Entomol. 96, 157-164.

Sinclair, B. J., Coello Alvarado, L. E., and Ferguson, L. V. (2015). An invitation to measure insect cold tolerance: Methods, approaches, and workflow. J. Therm. Biol. 53, 180-197. doi: 10.1016/j.jtherbio.2015.11.003

Sinclair, B. J., and Marshall, K. E. (2018). The many roles of fats in overwintering insects. J. Exp. Biol. 221:jeb161836. doi: 10.1242/jeb.161836

Šlachta, M., Vambera, J., Zahradníčková, H., and Košt’ál, V. (2002). Entering diapause is a prerequisite for successful cold-acclimation in adult Graphosoma lineatum (Heteroptera: Pentatomidae). J. Insect Physiol. 48, 1031-1039. doi: 10.1016/S0022-1910(02)00191-9

Sørensen, J. G., and Holmstrup, M. (2011). Cryoprotective dehydration is widespread in Arctic springtails. J. Insect Physiol. 57, 1147-1153. doi: 10.1016/j. jinsphys.2011.03.001

Storey, J. M., and Storey, K. B. (2004). "Cold hardiness and freeze tolerance," in Functional Metabolism, ed. K. B. Storey (Hoboken, NJ: John Wiley and Sons, Inc), 473-503. doi: 10.1002/047167558X.ch17

Storey, K. B., and Storey, J. M. (1991). "Biochemistry of Cryoprotectants," in Insects at Low Temperature, eds R. E. Lee Jr. and D. L. Denlinger (New York, NY: Chapman and Hall), 64-93. doi: 10.1007/978-1-4757-0190-6_4

Tan, Q. Q., Liu, W., Zhu, F., Lei, C. L., Hahn, D. A., and Wang, X. P. (2017). Describing the diapause-preparatory proteome of the beetle Colaphellus bowringi and identifying candidates affecting lipid accumulation using isobaric tags for mass spectrometry-based proteome quantification (iTRAQ). Front. Physiol 8:251. doi: 10.3389/fphys.2017.00251

Tanaka, K., and Ito, K. (2015). Accumulation of glycerol and myo-inositol in the overwintering nymphs of the wolf spider Pardosa astrigera (Araneae: Lycosidae). Acta Arachnol. 64, 1-4. doi: 10.2476/asjaa.64.1

Toxopeus, J., Koštál, V., and Sinclair, B. J. (2019). Evidence for non-colligative function of small cryoprotectants in a freeze-tolerant insect. Proc. Biol. Sci. 27:286. doi: 10.1098/rspb.2019.0050

Toxopeus, J., and Sinclair, B. J. (2018). Mechanisms underlying insect freeze tolerance. Biol. Rev. Camb. Philos. Soc. 93, 1891-1914. doi: 10.1111/brv.12425

Vrba, P., Nedvěd, O., Zahradníčková, H., and Konvička, M. (2017). More complex than expected: cold hardiness and the concentration of cryoprotectants in overwintering larvae of five Erebia butterflies (Lepidoptera: Nymphalidae). Eur. J. Entomol. 114, 470-480. doi: 10.14411/eje.2017.060

Walters, K. R., Pan, Q., Serianni, A. S., and Duman, J. G. (2009). Cryoprotectant biosynthesis and the selective accumulation of threitol in the freeze-tolerant Alaskan beetle, Upis ceramboides. J. Biol. Chem. 284, 16822-16831. doi: 10.1074/ jbc.M109.013870

Warburg, M. S., and Yuval, B. (1997). Effects of energetic reserves on behavioral patterns of Mediterranean fruit flies (Diptera: Tephritidae). Oecologia 112, 314-319. doi: 10.1007/s004420050314

Worland, M. R., Grubor-Lajšić, G., Purać, J., Thorne, M. A. S., and Clark, M. S. (2010). "Cryoprotective dehydration: Clues from an insect," in Dormancy and Resistance in Harsh Environments, eds E. Lubzens, J. Cerda, and M. Clark (Heidelberg: Springer), 147-163. doi: 10.1007/978-3-642-12422-8_9

Xiao, H., Chen, J., Chen, C., and Xue, F. (2015). Water and carbohydrate levels at different developmental stages and dynamics in hibernating pupae of Pieris melete (Lepidoptera: Pieridae). Entomol. Res. 45, 275-281. doi: 10.1111/17485967.12124

Yocum, G. D., Rinehart, J. P., and Larson, M. L. (2009). Down-regulation of gene expression between the diapause initiation and maintenance phases of the Colorado potato beetle, Leptinotarsa decemlineata (Coleoptera: Chrysomelidae). Eur. J. Entomol. 106, 471-476. doi: 10.14411/eje.2009.059

Yu, Z. J., Lu, Y. L., Yang, X. L., Chen, J., Wang, H., Wang, D., et al. (2014). Cold hardiness and biochemical response to low temperature of the unfed bush tick Haemaphysalis longicornis (Acari: Ixodidae). Parasites Vectors 7:346. doi: 10.1186/1756-3305-7-346

Zachariassen, K. E. (1985). Physiology of cold tolerance in insects. Physiol. Rev. 65, 799-832. doi: 10.1152/physrev.1985.65.4.799

Zhang, C., Wei, D., Shi, G., Huang, X., Cheng, P., Liu, G., et al. (2019). Understanding the regulation of overwintering diapause molecular mechanisms in Culex pipienspallens through comparative proteomics. Sci. Rep. 9:6485. doi: 10.1038/s41598-019-42961-w

Conflict of Interest: The authors declare that the research was conducted in the absence of any commercial or financial relationships that could be construed as a potential conflict of interest.

Copyright $\odot 2020$ Hasanvand, Izadi and Mohammadzadeh. This is an open-access article distributed under the terms of the Creative Commons Attribution License (CC BY). The use, distribution or reproduction in other forums is permitted, provided the original author(s) and the copyright owner(s) are credited and that the original publication in this journal is cited, in accordance with accepted academic practice. No use, distribution or reproduction is permitted which does not comply with these terms. 